\title{
Psychological Problems during Advance Stage of Pregnancy
}

\author{
Dr. Sanjay Kumar Nayak 1 , Rinku Poddar, 2 , Dr. Masroor Jahan 3
}

\section{ABSTRACT:}

Background: Physical changes can be seen throughout the pregnancy along with mood swings and other psychological or emotional reaction. Advance stage of pregnancy mainly during third trimester may affect more the women psychologically.

Purpose: Present study was conducted to expand the limited knowledge base regarding the potential psychological problems faced by women during the third trimester or advance stage of pregnancy.

Method: Psychological problems were investigated in 40 pregnant women 18- to 34 years old through Symptoms Checklist-90-R and General Health Questionnaire-28 during their third trimester. They were compared with 30 normal controls. Statistical analysis was done using SPSS (13.0 ver.).

Result: The result suggest that during advance stage/third trimester of pregnancy women experience psychological problems, namely, somatization, interpersonal sensitivity, depression, anger hostility, phobic anxiety, psychotism and disturbance in sleep and appetite and these symptoms may associate to their current age and duration of pregnancy.

Conclusion: Psychological factors during pregnancy and childbirth are important and that there can neglect can cause grave damage resulting in lifelong costs to the infant, parents and society. Women should formulate a treatment plan to manage common psychological problems too during pregnancy.

Keywords: Third Trimester, Childbirth, Pregnancy, Anxiety, Depression.

\section{INTRODUCTION:}

Understanding the impact of psychological problems faced by pregnant women, on their mental health and pregnancy, is vital for the well being of the mother and the child. While pregnancy is often considered as the golden period in a woman's life, there are a host of physical as well as mental challenges faced by them then, which usually go unnoticed.

\footnotetext{
${ }^{1}$ Assistant Professor, Deptt. Of Psychology, Jagadguru Rambhdracharya Handicapped University, Chitrakoot, U.P.

${ }^{2}$ M.Phil in Medical and Social Psychology, B/2, Nirmal Nagar, Hume Pipe Area, Sakchi, Jamshedpur, Jharkhand ${ }^{3}$ Associate Prof., Deptt. Of Clinical Psychology, Ranchi Institute of Neuro-Psychiatry and Allied Sciences, Ranchi, Jharkhand.
}

(C) 2015, S Nayak, R Poddar, M Jahan; licensee IJIP. This is an Open Access Research distributed under the terms of the Creative Commons Attribution License (http://creativecommons.org/licenses/by/2.0), which permits unrestricted use, distribution, and reproduction in any Medium, provided the original work is properly cited. 


\section{Psychological Problems during Advance Stage of Pregnancy}

Increasingly we are learning that the environment a baby is exposed to inside the womb is a very important long-term determinant of mental and physical health for the child. The common conception that a mother's psychological state can influence her unborn baby is to some extent substantiated by the literature. While the apparent physical problems associated with pregnancy are often addressed, it is the psychological challenges related to mental health and pregnancy, which often go unheeded. Although pregnancy and childbirth have gained some recognition, as significant risk factors in the development and exacerbation of mental health issues, most women are still unaware of the devastating effect of these conditions. As a matter of fact, nearly $20 \%$ of women suffer from mood or anxiety disorders during the gestation and postpartum periods, with the women with a previous history of mental problems being at an increased risk. However whether the condition affects the woman during pregnancy or post it, it can cause significant morbidity for the mother as well as the child. It is therefore vital that the patient be well informed about the risks involved on both sides and take into account her specific diagnosis and the recommendations of the health care provider.

\section{Common psychological problems during pregnancy}

Pregnancy and childbirth are developmental phases in the family life cycle with attendant psychological changes and stresses. Most healthy women have some distress ranging from the discomfort associated with abdominal enlargement and the discomforts of pregnancy to complications that cause disruption of work and restriction of social activities. The physiological processes of pregnancy are apt to provoke accompanying psychological phenomena. In fact, every physiological phase in the course of pregnancy has its specific psychological accompaniment. The surplus of innervations, the gradual organization of the somatic excitation processes, the changes in the circulation of the blood, the glandular functions and the process of nourishment of the tissues connected with pregnancy - all constitute an added physical strain that naturally must extend to the psychological sphere. These glandular or hormonal dysfunctions in women during pregnancy can cause vestibular and/or cochlear problem. Schmidt et al. (2010) observed in their study that tinnitus as a main auditory complaint was present among $33 \%$ of the pregnant women.

The degree of psychological stress associated with the process will vary depending on the women's developmental experiences, current life situation, and ability to adapt (Novak \& Broom, 1995).

The degree of acceptance is reflected in the woman's readiness for pregnancy and her emotional responses. The woman's attitude toward her pregnancy may be one of pride, acceptance, rejection or ambivalence. If the woman sees her pregnancy as an illness, she may perceive herself as unattractive, vulnerable, and uncomfortably dependent on other. These negative self-attitudes are likely to produce increased anxiety and irritability, which are then cycled through changes in the bloodstream to the foetus (e.g., de Muylder, 1989). 


\section{Psychological Problems during Advance Stage of Pregnancy}

Most researches in this area has focused on anxiety and depressive symptoms (Littleton et al. 2007), rather than other psychiatric problems.

There are various gestational or antepartum disorders that affect women during pregnancy and postpartum or postnatal mood disorders that occur after pregnancy as a result of physiological and hormonal changes. The common psychological problems that could be reported in previous studies are depression, anxiety, stress, OCD, phobic reaction, somatic disturbance, irritability, sleep disturbance etc.

A wide range of concerns unique to pregnant women has been identified as pregnancyspecific anxieties, stressors, or both (Arizmendi \& Affonso, 1987; DaCosta, Brender, \& Larouche, 1998; Huizink, Mulder, Robles de Medina, Visser, \& Buitelaar, 2004; Kumar, Robson, \& Smith, 1984; Yali \& Lobel, 1999). Because, pregnancy itself presents unique psychological challenges (Carlson \& LaBarba, 1979; Holmes \& Rahe, 1967; Zajicek \& Wolkind, 1978).

Though, psychological problems continued through first trimester to third trimester, overall among $14.1 \%$ of women were to be found suffering from psychiatric disorders during their second trimester, specially depression $3.3 \%$ to $6.9 \%$ and anxiety disorders $6.6 \%$ (Andersson et al. 2003; Bunevicius et al. 2009), panic disorder 2.5\% (Guler et al. 2008). Similarly, Kim et al. (2008) reported $7.7 \%$ and $6.8 \%$ of the women were at-risk range for depression during the third trimester and after delivery, respectively. The prevalence rate of OCD was reported 3.5\% among the women in the third trimester of pregnancy in which $0.5 \%$ developed OCD during the second trimester (Uguz et al. 2007).

Lopes et al. (2004) reported sleep disturbance during each trimester of pregnancy on their study conducted on 11-to-40 years-old pregnant women. They reported excessive daytime sleepiness by $14 \%$, mild sleepiness increased by $48 \%$ and the rate for specific awakenings increased by $84 \%$ during the third trimester.

The psychological adaptation to pregnancy varies with the course of pregnancy. In the first three months, intensive physiological changes such as nausea, vomiting, dizziness, headaches, and appetite disturbances, create and special kind of psychological stress for the expectant mother, which is the chief determinant of her emotional experiences. During the second three months, it is generally believed that women feel at their best both physically and mentally and that this period is a relatively tranquil time (Campbell \& Field, 1989). In the last three months, it appears that every woman experiences, somewhat, an approach - avoidance conflict about delivery. On the one hand, she expects to complete her pregnancy satisfactorily but on the other delivery promotes fear and anxiety. According to Miller's (1951) theory on conflict, the nearer the individual is to the goal in an approach - avoidance conflict, the higher the anxiety level. Thus, as the pregnant woman gradually adapts to her physiological state, the initial psychological stress declines, to be followed by a new kind of stress, characterized by 


\section{Psychological Problems during Advance Stage of Pregnancy}

anxiety, increase in emotional lability, tension, irritability, nightmares, depression, and insomnia (Rofe, Blittner, \& Lewin, 1993).

On the basis of the existing literature the goal of the current study was to expand the limited knowledge base regarding the potential psychological problems faced by women during the third trimester or advance stage of pregnancy.

\section{METHODOLOGY}

Sample - The sample for the present study consisted of forty women having third trimester of pregnancy and had no history of psychiatric illness attending outdoor gynecologic unit at subdivisional hospital, Chas, Bokaro and thirty non-pregnant women as normal control with no history of psychiatric illness to them or to their family were selected from different localities of Bokaro, Jharkhand. The mean age of pregnant women and normal control was $24.02 \pm 3.96$ and $24.70 \pm 4.04$ years respectively. The difference was statistically non-significant (t value $=0.69 ; \mathrm{df}$ $=68$ ). Other socio-demographic characteristics of caregivers are given in Table 1. Comparison shows that pregnant women who participated in the study did not differ statistically from normal participants in respect to education, marital status, socioeconomic status, religion and types of family. However, participants were statistically differing by living background. Though, no study could found suggesting the affect of living background in psychological health during pregnancy.

Tools - The following tools have been used for the collection of data in the present study:

Socio-demographic and clinical data sheet - This data sheet was specially designed and used to gather information about sample characteristics and clinical variables i.e. name, age, education, socioeconomic status, religion, types of family, duration of pregnancy, history of psychiatric illness etc.

Symptoms Checklist-90-R (SCL-90-R) - The SCL-90-R (Derogatis, L.R., 1994) is a 90-item, multidimensional self-report inventory designed to screen for a broad range of psychological problems and symptoms of psychopathology. There are nine primary symptom dimensions that are measured: somatization (perception of bodily dysfunction), obsessive-compulsive, interpersonal sensitivity (feelings of personal inadequacy or inferiority), depression, anxiety, hostility, phobic anxiety, paranoid ideation, psychotism and additional scale (items are poor appetite, trouble falling asleep, thought of death or dying, overeating, awakening in the early morning disturbed sleep, feelings of guilt). The respondent rates each item on 5-point scale which assesses the severity of the symptom.

General Health Questionnaire-28 - The GHQ-28 scale was derived by factor analysis of the original 60-item version (Goldberg and Hillier 1979) and prepared mainly for research purposes. The GHQ-28 incorporates four subscales: somatic symptoms, anxiety and insomnia, social dysfunction, and severe depression. The respondent rates each GHQ-28 item on 4-point scale which assesses the severity of the symptom within past few weeks. The scale score ranges are 0 


\section{Psychological Problems during Advance Stage of Pregnancy}

(for first two options) and 1 (for last two options). The maximum possible raw GHQ-28 total score is 28 . The cut-off score is 5 .

\section{RESULT}

Psychological problems were assessed using symptoms checklist-90-R and General health questionnaire-28. To compare the psychological problems of pregnant and Non-pregnant women on the different variables of SCL-90-R and GHQ-28 t-test was applied. Result shows that both groups were statistically differ on somatization, interpersonal sensitivity, depression, anger hostility, phobic anxiety, psychotism and additional scale variables of SCL-90-R (table -2). But statistically no significant difference was found between both groups on GHQ-28 variables (table-3). This might be due to low in severity of the presented symptoms by the pregnant women. The result suggest that women during their advance stage of pregnancy experience some kind of psychological problem i.e. somatization, interpersonal sensitivity, depression, anger hostility, phobic anxiety, psychotism and other additional psychological problems e.g. disturbed sleep, disturbed appetite, and guilt and death ideas.

Further, the severity of the psychological problems among pregnant women may associate to their current age and duration of pregnancy. Results (table 4) show significant positive correlation between age of pregnant women and the following variables of SCL-90 e.g. somatization, interpersonal sensitivity, depression, anger hostility, paranoid ideation and psychotism. Similarly positive correlation was found between duration of pregnancy and interpersonal sensitivity, psychotism and additional scale. Though, there was no significant correlation was found between current age of pregnant women and GHQ-28 variables (table 5) and duration of pregnancy and GHQ-28 variables (table 5).

\section{DISCUSSION}

This is, to our knowledge, though many studies examining emotional difficulties during different trimester of pregnancy mainly focused to anxiety and depressive symptoms. We highlight in the present study to the nature of other psychological problems including anxiety and depression experiencing by women during their third trimester or advance stage of pregnancy and the association of these psychological problems with age and duration of pregnancy.

The data demonstrated that women during third trimester of pregnancy experienced various levels of psychological difficulties than non-pregnant women of similar age group and other socio-demographic status. The pregnant women during third trimester experienced more somatization, interpersonal sensitivity, depression, anger hostility, phobic anxiety, psychotism and disturbance in sleep and appetite than non-pregnant women. Our results are in accord with some of the previous findings but not for all. For example, depressive symptoms (Kim, et al., 2008; Evans, et al., 2001; Brooks, 2009), sleep disturbance (lopes, et al., 2004; Ko, et al., 2010), 


\section{Psychological Problems during Advance Stage of Pregnancy}

pregnancy specific anxieties (DaCosta, et al., 1998; Huizink, et al., 2004) were also reported during third trimester in previous findings. In the present study the symptoms of OCD, anxiety and paranoid ideation could not be elicited during third trimester of pregnancy. Though, previous findings reported OCD (Uguz, et al., 2007; Forray, et al., 2010) during perinatal period or third trimester. This variation might be because of higher frequencies of family of OCD (Uguz, et al., 2007) or preexisting disorder (Forray, et al., 2010) in previous studies.

The present study suggested that age and duration of pregnancy definitely has an impact on the psychological problems in women during third trimester. The possibility is that the earlier age of pregnancy might develop more psychological problems because of lesser previous experience in this regard. However, no review literature could be found such findings and need further study to elaborate the reason. Similarly, duration of pregnancy also affect pregnant women's interpersonal sensitivity, paranoid ideation and sleep and appetite disturbance. Although previous study suggested variation in depressive disorder during second and third trimester of pregnancy (Bunevicius, et al., 2009) however, there is no significant association could be found between duration of pregnancy and depression.

Since cross-sectional assessment was done in the present study, causal inference could not be drawn. However literature suggests that each trimester of pregnancy adapts a different physiological state to be followed by a new kind of stress, i.e. anxiety, emotional lability, tension, irritability, nightmares, depression, insomnia etc (Rofe, et al. 1993). Another possibility is that during advance stage of pregnancy the psychological as well as social role is changed that restrict their social and physical activity might increase psychological problems.

The present study tries to find out the nature of psychological problems among pregnant women during their third trimester or advance stage and its association with some clinical variables and it was found that pregnant women experiencing it during their third trimester or advance stage. Though, this study could not assessed the causal factors and whether the severity was up to diagnostic level, further study are needed on large sample size including confounding variables.

\section{CONCLUSION}

While the effect of psychotropic medications during pregnancy is no ascertained, the risk associated with untreated psychological problems during and after pregnancy has to be taken into consideration and necessary treatment should be provided. One of the best treatments for psychological problems during pregnancy is psychotherapy. Not only is psychotherapy completely safe and healthy, for both the mother and the child, it also works to find out the root cause of the psychological problems. Since, women clearly benefited from support before and after childbirth it is advisable that before taking any medicine to reduce or eliminate such problems, a health care provider is consulted and should be explained the risks of medication to the unborn child or the infant through breast milk. One study showed that counseling for women who are depressed when pregnant may help to prevent problems for the family after the baby is 
born (Brooks, 2009). Since mental health and pregnancy are synonymous with the well being the mother and the child, women should formulate a treatment plan to manage these common problems.

Table 1 - Showing socio-demographic characteristics of the participants

\begin{tabular}{|c|c|c|c|c|c|c|}
\hline \multirow{3}{*}{\multicolumn{2}{|c|}{ Socio-demographic variables }} & \multicolumn{4}{|c|}{ Group } & \multirow{3}{*}{$\begin{array}{c}t \\
(\mathrm{df}=68)\end{array}$} \\
\hline & & \multicolumn{2}{|c|}{$\begin{array}{c}\text { Pregnant } \\
\text { Women } \\
(\mathrm{N}=40)\end{array}$} & \multicolumn{2}{|c|}{$\begin{array}{c}\text { Non-Pregnant } \\
\text { Women } \\
(\mathbf{N}=\mathbf{3 0})\end{array}$} & \\
\hline & & Mean & SD & Mean & SD & \\
\hline \multirow{2}{*}{\multicolumn{2}{|c|}{ Age }} & 24.02 & 3.96 & 24.70 & 4.04 & 0.69 \\
\hline & & \multicolumn{2}{|c|}{$\mathbf{N}(\%)$} & \multicolumn{2}{|c|}{$\mathbf{N}(\%)$} & $\chi^{2}$ \\
\hline \multirow{4}{*}{ Education } & Illiterate & \multicolumn{2}{|c|}{$10(25.0)$} & \multicolumn{2}{|c|}{$8(26.7)$} & \multirow{4}{*}{$\begin{array}{l}3.555 \\
(3)\end{array}$} \\
\hline & Up to primary & \multicolumn{2}{|c|}{$9(22.5)$} & \multicolumn{2}{|c|}{$2(6.7)$} & \\
\hline & Up to secondary & \multicolumn{2}{|c|}{$12(30.0)$} & \multicolumn{2}{|c|}{$10(33.3)$} & \\
\hline & $\begin{array}{l}\text { Higher secondary } \\
\text { and above }\end{array}$ & \multicolumn{2}{|c|}{$9(22.5)$} & \multicolumn{2}{|c|}{$14(33.3)$} & \\
\hline \multirow[b]{2}{*}{ Marital Status } & Married & \multicolumn{2}{|c|}{$40(100.0)$} & \multicolumn{2}{|c|}{$28(93.3)$} & \multirow{2}{*}{$\begin{array}{l}2.745 \\
(1)\end{array}$} \\
\hline & Unmarried & \multicolumn{2}{|c|}{$0(0.0)$} & \multicolumn{2}{|c|}{$4(13.3)$} & \\
\hline \multirow[b]{3}{*}{$\begin{array}{l}\text { Living } \\
\text { Background }\end{array}$} & Rural & \multicolumn{2}{|c|}{$2(5.0)$} & \multicolumn{2}{|c|}{$4(13.3)$} & \multirow{3}{*}{$\begin{array}{c}10.839 * \\
* \\
(2)\end{array}$} \\
\hline & Urban & \multicolumn{2}{|c|}{$22(55.0)$} & \multicolumn{2}{|c|}{$5(16.7)$} & \\
\hline & Semi Urban & \multicolumn{2}{|c|}{$16(40.0)$} & \multicolumn{2}{|c|}{$21(70.0)$} & \\
\hline \multirow[b]{2}{*}{$\begin{array}{l}\text { Socioeconomic } \\
\text { Status }\end{array}$} & Lower & \multicolumn{2}{|c|}{$18(45.0)$} & \multicolumn{2}{|c|}{$11(36.7)$} & \multirow[b]{2}{*}{$\begin{array}{c}0.491 \\
(1)\end{array}$} \\
\hline & Middle & $22(5$ & & 19 & & \\
\hline & Hindu & $35(\varepsilon$ & & 28( & & \\
\hline Religion & Islam & $5(1$ & & 2( & & $\begin{array}{c}0.648 \\
(1)\end{array}$ \\
\hline Types of Family & Nuclear & $11(2$ & & $7(2$ & & 0.156 \\
\hline & Joint & 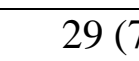 & & 24 & & (1) \\
\hline
\end{tabular}


Table 2 - Showing differences between Pregnant and Non-Pregnant group on SCL-90

\begin{tabular}{|c|c|c|c|c|c|}
\hline \multirow{3}{*}{ SCL-90 variables } & \multicolumn{4}{|c|}{ Group } & \multirow{3}{*}{$\begin{array}{c}t \\
(d f=68)\end{array}$} \\
\hline & \multicolumn{2}{|c|}{$\begin{array}{l}\text { Pregnant Women } \\
(\mathbf{N}=\mathbf{4 0})\end{array}$} & \multicolumn{2}{|c|}{$\begin{array}{c}\text { Non-Pregnant Women } \\
\qquad(\mathbf{N}=\mathbf{3 0})\end{array}$} & \\
\hline & Mean & SD & Mean & SD & \\
\hline Somatization & 13.625 & 8.393 & 8.966 & 5.738 & $2.614 *$ \\
\hline Obsessive-Compulsive & 11.025 & 6.447 & 8.333 & 5.060 & 1.890 \\
\hline Interpersonal Sensitivity & 11.650 & 6.604 & 8.000 & 4.828 & $2.556^{*}$ \\
\hline Depression & 16.750 & 9.558 & 11.766 & 6.698 & $2.439 *$ \\
\hline Anxiety & 10.150 & 6.981 & 7.466 & 4.861 & 1.801 \\
\hline Anger Hostility & 6.250 & 4.667 & 4.266 & 2.790 & $2.065^{*}$ \\
\hline Phobic Anxiety & 5.650 & 3.408 & 4.000 & 3.216 & $2.053^{*}$ \\
\hline Paranoid Ideation & 6.800 & 5.029 & 6.166 & 3.696 & 0.582 \\
\hline Psychotism & 9.575 & 6.679 & 4.800 & 4.122 & $3.450^{* * *}$ \\
\hline Additional Scale & 7.825 & 5.329 & 5.400 & 4.231 & $2.053^{*}$ \\
\hline
\end{tabular}

Significant at the level of .05

Table 3 - Showing differences between Pregnant and Non-Pregnant group on GHQ-28

\begin{tabular}{|c|c|c|c|c|c|}
\hline \multirow[t]{3}{*}{ GHQ-28 variables } & \multicolumn{4}{|c|}{ Group } & \multirow{3}{*}{$\begin{array}{c}t \\
(d f=83)\end{array}$} \\
\hline & \multicolumn{2}{|c|}{$\begin{array}{l}\text { Pregnant Women } \\
\qquad(\mathrm{N}=40)\end{array}$} & \multicolumn{2}{|c|}{$\begin{array}{c}\text { Non-Pregnant } \\
\text { Women } \\
(\mathbf{N}=\mathbf{3 0})\end{array}$} & \\
\hline & Mean & SD & Mean & SD & \\
\hline Somatic Complain & 3.050 & 2.159 & 2.366 & 2.141 & 1.315 \\
\hline Anxiety \& Insomnea & 2.900 & 2.097 & 2.033 & 2.498 & 1.576 \\
\hline Social Dysfunction & 1.975 & 1.775 & 1.466 & 1.814 & 1.174 \\
\hline Severe Depression & 2.600 & 2.580 & 1.800 & 2.426 & 1.317 \\
\hline Total Score on GHQ-28 & 10.525 & 6.656 & 7.666 & 7.250 & 1.711 \\
\hline
\end{tabular}


Table 4 - Showing correlation between age, duration of pregnancy and SCL-90 variables

\begin{tabular}{|l|l|l|}
\hline \multicolumn{3}{|c|}{$\mathbf{N = 4 0}$} \\
\hline $\begin{array}{c}\text { SCL-90 variables } \\
\downarrow\end{array}$ & $\begin{array}{c}\text { Age of Pregnancy } \\
\text { (in year) }\end{array}$ & $\begin{array}{c}\text { Duration of Pregnancy } \\
\text { (in month) }\end{array}$ \\
\hline Somatization & $.388^{*}$ & .287 \\
\hline Obsessive-Compulsive & .214 & .187 \\
\hline Interpersonal Sensitivity & $.343^{*}$ & $.419^{* *}$ \\
\hline Depression & $.362^{*}$ & .160 \\
\hline Anxiety & .291 & .296 \\
\hline Anger Hostility & $.354^{*}$ & .222 \\
\hline Phobic Anxiety & .029 & .199 \\
\hline Paranoid Ideation & $.459^{* *}$ & .297 \\
\hline Psychotism & $.444^{* *}$ & $.468^{* *}$ \\
\hline Additional Scale & .217 & $.502^{* *}$ \\
\hline$* *$ Correlation is significant at the 0.01 level (2-tailed), & $*=$ Correlation is \\
\hline
\end{tabular}
significant at the 0.05 level (2-tailed)

Table 5 - Showing correlation between age, duration of pregnancy and GHQ-28 variables

\begin{tabular}{|l|c|c|}
\hline \multicolumn{2}{|c|}{$\mathbf{N = 4 0}$} \\
\hline $\begin{array}{c}\text { GHQ-28 variables } \\
\downarrow\end{array}$ & $\begin{array}{c}\text { Age of pregnancy } \\
\text { (in year) }\end{array}$ & $\begin{array}{c}\text { Duration of } \\
\text { Pregnancy } \\
\text { (in month) }\end{array}$ \\
\hline Somatic Complain & .069 & .192 \\
\hline Anxiety \& Insomnea & .096 & .278 \\
\hline Social Dysfunction & .109 & .102 \\
\hline Severe Depression & .274 & .284 \\
\hline Total Score on GHQ-28 & .188 & .287 \\
\hline
\end{tabular}

$* *=$ Correlation is significant at the 0.01 level $(2$-tailed $), *=$ Correlation is significant at the 0.05 level (2-tailed)

\section{REFERENCE}

1. Andersson L, Sundstrom-Poromaa I, Bixo M, Wulff M, Bomdestam K, åStröm M (2003) Point prevalence of psychiatric disorders during the second trimester of pregnancy: a population-based study. American Journal of Obstetrics and Gynecology 189:148-154.

2. Arizmendi T, Affonso D (1987) Stressful events related to pregnancy and postpartum. Journal of Psychosomatic Research 31:743-756.

3. Brooks P (2009) Can antenatal counseling prevent postnatal depression? Healthcare Counselling and Psychotherapy Journal 9:29-32.

4. Bunevicius R, Kusminskas L, Bunevicius A, Nadisauskiene RJ, Jureniene K, Pop VJ (2009) Psychosocial risk factors for depression during pregnancy. Acta Obstetricia et Gynecologica Scandinavica 88:599-605. 


\section{Psychological Problems during Advance Stage of Pregnancy}

5. Campbell IE, Field PA (1989) Common psychological concerns experienced by parents during pregnancy. Canada's Mental Health 37:2-5

6. Carlson D, La Barba R (1979) Maternal emotionality during pregnancy and reproductive outcome: A review of the literature. International Journal of Behavioral Development 2:343-376.

7. DaCosta D, Brender W, Larouche J (1998) A prospective study of the impact of psychosocial and lifestyle variables on pregnancy complications. Journal of Psychosomatic Obstetrics and Gynecology 19:28-37

8. de Muyider X (1989) Psychological factors and preterm labor. Journal of Reproductive \& Infant Psychology 7:55-57

9. Derogatis LR (1994) Symptom Checklist-90-R: Administration, scoring and procedures manual, $3^{\text {rd }}$ edition, National Computer Systems, Inc., Minneapolis, MN 55440.

10. Evan J, Heron J, Francomb H, Oke S, Golding J, on behalf of the Avon Longitudinal study of Parents and Children Study Team (2001). Cohort study of depressed mood during pregnancy and after childbirth. British Medical Journal, 323, 257-260.

11. Forray A, Focseneanu M, Pittman B, McDougle CJ, Epperson CN (2010) Onset and exacerbation of obsessive-compulsive disorder in pregnancy and the postpartum period. The Journal of Clinical Psychiatry 71:1061-1068.

12. Goldberg DP, Hillier VF (1979) A scaled version of the General Health Questionnaire. Psychological Medicine 9:139-45.

13. Guler O, Sahin FK, Emul HM, Ozbulut O, Gecici O, Uguz F, Gezginc K, Zeytinci IE, Karatayli S, Askin R (2008) The prevalence of panic disorder in pregnant women during the third trimester of pregnancy. Comprehensive Psychiatry 49:154-158.

14. Holmes TH, Rahe RH (1967) The social readjustment rating scale. Journal of Psychosomatic Research 11:213-218.

15. Huizink A, Mulder E, Robles de Medina P, Visser G, Buitelaar J (2004) Is pregnancy anxiety a distinctive syndrome? Early Human Development 79:81-91

16. Kim JJ, Gordon TE, La Porte LM, Adams M, Kuendig JM, Silver RK (2008) The utility of maternal depression screening in the third trimester. American Journal of Obstetrics and Gynecology 199:509.e1-5.

17. Ko SH, Chang SC, Chen CH (2010) A comparative study of sleep quality between pregnant and nonpregnant Taiwanese women. Journal of Nursing Scholarship: an official publication of Sigma Theta Tau International Honor Society of Nursing/Sigma Theta Tau 42:23-30.

18. Kumar R, Robson KM, Smith AMR (1984) Development of a self-administered questionnaire to measure maternal adjustment and maternal attitudes during pregnancy and after delivery. Journal of Psychosomatic Research 28:43-51.

19. Littleton HL, Breitkopf CR, Berenson AB (2007) Correlates of anxiety symptoms during pregnancy and association with perinatal outcomes: a meta-analysis. American Journal of Obstetrics and Gynecology 196:425-432. 


\section{Psychological Problems during Advance Stage of Pregnancy}

20. Lopes EA, Carvalho LB, Seguro PB, Mattar R, Silva AB, Prado LB, Prado GF (2004) Sleep disorder in pregnancy. Arquivos de Neuro-psiquiatria 62:217-221.

21. Miller NE (1951) Comments on theoretical models: illustrated by the development of a theory of conflict behavior. Journal of Personality 20:82-100

22. Novak JC, Broom BL (1995) Ingalls \& Sallerno's maternal and child health nursing $\left(8^{\text {th }}\right.$ ed). St. Louis: Mosby.

23. Rofé Y, Blittner M, Lewin I (1993) Emotional experiences during the three trimesters of pregnancy. Journal of Clinical Psychology 49:3-12

24. Schmidt PM, Flores Fda T, Rossi AG, Silveira AF (2010) Hearing and vestibular complaints during pregnancy. Brazilian Journal of Otorhinolaryngology 76:29-33.

25. Uguz F, Gezginc K, Zeytinci IE, Karatayli S, Askin R, Guler O, Sahin FK, Emul HM, Ozbulut O, Gecici O (2007) Obsessive-compulsive disorder in pregnant women during the third trimester of pregnancy. Comprehensive Psychiatry 48:441-445.

26. Yali A, Lobel M (1999) Coping and distress in pregnancy: An investigation of medically high risk women. Journal of Psychosomatic Obstetrics and Gynecology 20:39-52.

27. Zajicek E, Wolkind S (1978) Emotional difficulties in married women during and after the first pregnancy. British Journal of Medical Psychology 51:379-385. 